\title{
Narrativas audiovisuais de mulheres negras no youtube e mobilização de processos formativos
}

\author{
Tatiana Paz \\ Eduardo Junqueira
}

\section{Resumo}

Neste artigo busca-se analisar como os conteúdos das narrativas audiovisuais construídas e compartilhadas por mulheres negras em um site de rede social podem mobilizar processos formativos. As análises apresentadas são baseadas no conteúdo de 12 vídeos postados nos canais de 3 mulheres negras no Youtube e na observação das suas ações em rede, especialmente nesta rede social. A metodologia da pesquisa teve um caráter etnográfico e as principais técnicas de pesquisa foram observação participante e entrevista semiestruturada. As ações dessas mulheres apontam apropriações midiáticas de caráter político, sobre identidades estéticas, que proporcionam processos formativos centrados em seus relatos biográficos, nas suas vivências sócio raciais e na construção de narrativas acerca da formação das identidades de mulheres negras.

Palavras-chave: Processos formativos. Mulheres negras. Narrativas audiovisuais.

\section{Audiovisual narratives of black women on youtu- be and mobilization of formative processes}

\section{Abstrat}

This article aims to analyze how the contents of audiovisual narratives constructed and shared by black women in a social network website can mobilize formative processes. The analyzes presented are based on the content of 12 videos posted on the channels of 3 black women on Youtube and the observation of their actions in network, especially in this social network website. The methodology of the research had an ethnographic character and the 
main research techniques were participant observation and semi- structured interview. The actions of these women point to political appropriations of aesthetic identities that provide formative processes centered on their biographical narratives, their racial experiences and the construction of narratives about the formation of black women's identities.

Keywords: Formative processes. Black women. Audiovisual narratives.

\section{Narrativas audiovisuales de mujeres negras en el youtube y movilización de procesos formativos}

\section{Resumen}

En este artículo se busca analizar cómo los contenidos de las narrativas audiovisuales construidas y compartidas por mujeres negras en un sitio de red social pueden movilizar procesos formativos. Los análisis presentados se basan en el contenido de 12 videos publicados en los canales de 3 mujeres negras en Youtube y en la observación de sus acciones en red, especialmente en esta red social. La metodología de la investigación tuvo un carácter etnográfico y las principales técnicas de investigación fueron observación participante y entrevista semiestructurada. Las acciones de esas mujeres apuntan apropiaciones mediáticas de carácter político, sobre identidades estéticas, que proporcionan procesos formativos centrados en sus relatos biográficos, en sus vivencias socio raciales y en la construcción de narrativas sobre la formación de las identidades de mujeres negras.

Palabras clave: Procesos formativos. Mujeres negras. Narraciones audiovisuales

\section{Introdução}

Os processos de dominação vividos durante a colonização no Brasil resultaram em uma construção ideológica de inferiorização dos povos afrodescendentes. Este processo de marginalização, que atinge as mais diversas esferas da vida cotidiana de pessoas negras no país, é questionado por sujeitos e grupos que resistem ao racismo de variadas formas.

Vivemos em um campo de tensões e de relações de poder em que ainda questionam-se as concepções, representações e estereótipos sobre a África, os africanos, os negros brasileiros e sua cultura, construídos histórica e socialmente nos processos de domina- 
ção, colonização e escravização (GOMES, 2012). Mulheres negras construíram ao longo do tempo suas próprias narrativas na busca por romper com as opressões de gênero, raça e classe (HOOKS, 2015; DAVIS, 2016; BARROS, 2009; CARNEIRO 1995). Como seres imersos histórica e socialmente, tais lutas foram permeadas pelas práticas e tecnologias do seu tempo, hoje marcadas pelo uso dos dispositivos computacionais para o engajamento em trocas comunicacionais nos sites de redes sociais.

Em um contexto em que as redes digitais de comunicação ampliaram as possibilidades e formas de atuação dos sujeitos engajados em diversas causas e movimentos sociais, por meio das redes sociais digitais na internet, investigamos, no escopo da referida pesquisa, também o caráter da ação discursiva midiática de mulheres ${ }^{1}$ negras na plataforma online Youtube e com isso buscamos contribuir com a compreensão sobre como se articulam processos formativos no contexto da cibercultura.

Assim, busca-se compreender de que maneira a produção de narrativas audiovisuais de mulheres negras no Youtube pode proporcionar processos formativos descolonizadores aos seguidores de seus canais na plataforma digital. Para isso, realizou- se uma pesquisa de caráter etnográfico cujos resultados foram construídos através da observação nos canais de três mulheres negras no Youtube e entrevistas às mesmas.

\section{Referencial Teórico}

A pesquisa aqui relatada se situa na busca por compreender como a cibercultura (LEMOS, 2010, 2007, 2004; RUDIGER, 2003; LEVY, 1999; HIMANEN, 2001) também possibilitou a ampliação das formas de atuação política de mulheres negras (HOOKS, 2015; DAVIS, 2016; BARROS, 2009; CARNEIRO 1995) que constroem e disputam "novas" narrativas sobre as suas identidades através do uso das novas tecnologias digitais e das trocas comunicacionais

\footnotetext{
${ }^{1}$ Rede social online de compartilhamento de vídeos: www.youtube.com
} 
em rede e como a produção destas narrativas audiovisuais podem se articular processos formativos (MACEDO, 2013; JOSSO, 2002; DOMINICÈ, 2006).

Compreender a articulação de processos formativos protagonizados por mulheres negras no Youtube requer um olhar acerca da natureza dos mesmos, como eles assumem especificidades advindas das trocas de saberes possibilitadas pelo digital em rede, e das próprias questões raciais que estruturam as narrativas produzidas por estas mulheres negras. Para isso, neste artigo, partimos da discussão acerca do campo conceitual de formação com enfoque numa perspectiva experiencial, refletimos sobre as apropriações políticas do ciberespaço como possíveis fluxos de saberes que compõem tais processos formativos, e buscamos tensionar esses campos a partir das questões raciais que atingem as participantes da pesquisa e mobilizam a produção de narrativas audiovisuais.

A discussão sobre processos formativos agrega diferentes abordagens acerca dos significados do termo formação (PIMENTA, 2008; CANDAU, 1983; FARIAS et al, 2014). Historicamente o seu conceito tem se modificado como um sentido em constante negociação, ainda que seja comumente associado aos processos formais de ensino.

Frequentemente, agregam ao significado de formação aquilo que é exterior ao sujeito, estritamente associado a uma ação ou atividade que ocorre nas instituições de ensino. Ainda que estas perspectivas de formação sejam importantes e válidas no campo da educação, o caráter das experiências analisadas de mulheres negras no Youtube requer um olhar sobre os processos formativos que não se restringe aos âmbitos formais de aprendizagem, mas que são constituídos no fluxo das experiências cotidianas.

Assim, partimos da compreensão de que a formação não é uma ação simples, determinada por fatores exclusivamente externos, não é um método, não é uma técnica, não é um processo de maturação, não pode ser confundida simplesmente com educação, nem com ensino ou aprendizagem, assim como não é a capa- 
cidade de um sujeito de guardar informações (MACEDO, 2013). A formação é experiencial e se desenvolve como uma atividade consciente do sujeito, que efetua uma aprendizagem imprevista ou voluntária em termos de competências existenciais, instrumentais ou pragmáticas, na ocasião de um acontecimento, de uma situação, ou de uma atividade que põe o sujeito em interação com ele próprio, com os outros, com o ambiente natural ou com as coisas (JOSSO, 2002).

A concepção de formação não pode ser restrita somente ao resultado de um evento educativo formal. Trata-se de um fenômeno com um significado mais amplo, mais global, que inclui diferentes facetas da vida de uma pessoa. Para Dominicè (2006), toda formação tem uma história a ser narrada, e essa narrativa revela um processo múltiplo que só se interrompe com a morte.

\section{Mulheres negras e a articulação de processos formativos em rede}

A formação envolve um processo de significação das histórias de vida com as complexidades e contradições das experiências, num dado contexto social e histórico. As biografias de mulheres negras de múltiplas gerações, por exemplo, ainda que atravessadas historicamente pelas mesmas opressões - gênero, raça e classe - assumem especificidades nas formas de vivenciar e enfrentar estas problemáticas sociais. Tais experiências de enfrentamento fazem parte dos seus processos formativos através das suas construções identitárias constituídas por escolhas, negociações, renúncias, etc.

Para a compreensão destes percursos, é importante considerar a experiência como elemento fundante dos processos formativos destas mulheres. Esta ótica inclui a percepção de que o conhecimento científico e acadêmico na formação de um indivíduo é mais uma referência importante, e não a única referência, que produz compreensões sobre uma faceta da realidade. A partir desse olhar, surge a necessidade de valorizar a construção de processos formativos que incluam outras referências de conhecimento. 
Ao refletirmos sobre as narrativas construídas pelas mulheres negras no Youtube, partimos do pressuposto de que os processos formativos se constituem na relação entre o sujeito e o seu contexto sócio-histórico. Com isso, consideramos que a formação é sempre singular, mas esta singularidade se constrói pelos percursos socializados, habitados por heranças coletivas dos sujeitos (DOMINICÈ, 2006).

No contexto das novas e renovadas vivências dos atores na cibercultura, os processos formativos ampliaram suas formas e contextos. As tecnologias digitais vêm estruturando novas relações sociotécnicas, entre as quais podemos destacar a produção e socialização interativa de conhecimentos no ciberespaço na relação dos atores com as tecnologias (SANTOS, 2002). Compreende-se as esferas do digital em rede como campos legítimos de formação, e atribui-se a elas o status de redes educativas, já que a formação acontece em múltiplos contextos (idem, 2011), como nos diferentes aparelhos culturais das cidades, nos movimentos sociais, nos espaços religiosos, instituições educacionais, bem como através das redes digitais de informação e comunicação.

A tecnologia, neste sentido, pode se tornar um elemento importante para a construção existencial dos sujeitos imersos nestas redes e fluxos comunicacionais. A premissa dos cyberpunks - "do it yourself" - explora essa possibilidade ao propor uma apropriação da técnica de forma política e social: "[...] Faça você mesmo de sua vida uma obra de arte, aqui e agora [...]. Explore as possibilidades simbólicas e concretas da utilização dos objetos técnicos. Pegue em suas mãos o destino tecnológico do planeta. Comunique, troque, toda a informação é boa e deve ser livre [...]" (LEMOS, 2010, p.

198). Essas apropriações simbólicas da técnica, sugeridas pelos cyberpunks, apontam para as possibilidades de construções de narrativas políticas e humanas no ciberespaço que dialogam com a perspectiva de processos formativos construída por Dominicè (2006), que destaca a formação como uma experimentação existencial que ocorre durante uma constante busca de si. 
De acordo com Jungblut (2015), as “ações políticas" no ciberespaço ou "ciberacontecimentos" podem gerar questões que se estruturam sobre a) as negociações e percepções de realidade ali ocorrem, b) os tipos de engajamentos identitários que suscita nos atores desta experiência, e sobre c) a tessitura das relações sociais que neles ocorrem. Tais questionamentos indicam que as ações políticas vivenciadas no ciberespaço podem se aproximar de uma busca por sentido à existência e às experiências, através das percepções das realidades compartilhadas, dos engajamentos produzidos e das relações sociais que ali se estabelecem.

Nesse sentido, é notório perceber que as redes colaborativas proporcionadas pelas tecnologias digitais colocam em cena novos mediadores e produtores de narrativas que surgem como um discurso político "fora de lugar" que não tem origem na universidade, no Estado, na mídia tradicional, ou em um partido político, mas na voz de indivíduos que “[...] passam de 'objetos' a sujeitos do discurso, contribuindo com uma renovação do político, e com os discursos mais contundentes sobre racismo, violência policial, pobreza, concorrendo com os discursos da universidade e da mídia." (idem, 2009, p. 55). ${ }^{2}$

Para Zelinda Barros (2009), as tecnologias digitais permitiram conectar, em muito menos tempo, ativistas geograficamente dispersas, além de criar um campo de atuação, dada a especificidade da cibercultura, que cria espaços de "reforço à prática feminista negra". Para ela, com a Internet, as mulheres negras se apropriaram de mecanismos que fazem com que suas vozes ecoem cada vez mais longe, lançando as bases para uma articulação em rede potencializada por tecnologias como a Internet.

Através da interlocução com outras pessoas, os sujeitos constroem uma compreensão de si mesmo, e as mídias proporcionam o fluxo das trocas comunicativas que permitem o compartilhar das questões sociais que os atingem. Neste contexto de apropriação

2 Disponível em https://www.academia.edu/1497162/Feminismo_negro_ na_Internet. Acesso em 12 de janeiro de 2017. 
política das redes sociais, apresentamos a prática comunicacional de três mulheres negras no Youtube acerca das suas identidades.

\section{Procedimentos Metodológicos}

A metodologia da pesquisa tem um caráter etnográfico e os procedimentos metodológicos foram organizados em duas principais ações: observação nos canais de três mulheres negras e entrevistas às mesmas a partir dos preceitos etnográficos. Assim, as principais técnicas de pesquisa foram a observação participante e a entrevista semiestruturada (FRAGOSO et. al., 2012).

Assim, na pesquisa etnográfica as ações das pessoas são estudadas no seu contexto habitual e não através de condições artificiais criadas pelo pesquisador. As informações são acessadas através de fontes diversas como a observação participante, conversação informal e entrevistas que não são feitas através de um plano de trabalho com categorias de interpretação preestabelecidas.

$\mathrm{Na}$ etnografia, o pressuposto metodológico básico consiste em estudar nós mesmos como se fôssemos o outro, realizando um processo de estranhamento a tudo aquilo que lhe é familiar. Já o pressuposto teórico reporta-se ao conhecimento de trabalhos etnográficos e dos principais teóricos da disciplina. Juntos, o estranhamento e o saber antropológico serão fundamentais ao pesquisador na percepção e seleção de fatos e acontecimentos, bem como na sua articulação com o corpo teórico para análise dos dados etnográficos (ROMANELLI, 1998). Portanto, constituem pressupostos epistemológicos centrais da pesquisa etnográfica o estranhamento, a compreensão da realidade a partir da perspectiva dos nativos e a reflexividade.

As análises apresentadas neste artigo foram baseadas nos conteúdos de 12 vídeos publicados nos canais de três mulheres negras no Youtube, através de entrevistas em profundidade realizadas com essas mulheres e na observação das suas ações na rede e em rede. 


\section{Narrativas audiovisuais de mulheres negras no Youtube}

As ações comunicacionais protagonizadas pelas três mulheres negras entrevistadas nesta pesquisa se desenvolvem de forma geral em torno da questão da identidade estética da mulher negra. Estas temáticas se ampliam para outras questões que envolvem as identidades das mulheres negras, ou seja, as narrativas construídas nos canais expandem o espectro das discussões, que passam a envolver questões como feminismo negro, solidão da mulher negra, colorismo, empreendedorismo, gordofobia, diversidade de gênero, etc. A análise que se inicia apresenta narrativas audiovisuais de três mulheres que assumem, como temática principal dos seus canais, as identidades estéticas das mulheres negras.

As narrativas audiovisuais produzidas por essas mulheres têm em comum a) a temática central dos canais (identidade estética das mulheres negras), b) relação direta das narrativas com as suas histórias de vida, c) suas experiências com o racismo, e o d) interesse por apoiar outras mulheres negras no enfrentamento do racismo na sua vida cotidiana. Frequentemente as mesmas evocam experiências vividas na infância, adolescência, e também na vida adulta, relacionadas às questões raciais e suas experiências são relatadas a um público com o qual possuem identificações. Em um dos seus vídeos, Luciellen Assis destina a sua mensagem a uma possível audiência formada por outras mulheres negras, que provavelmente tiveram a autoestima afetada pelo racismo.

Esse vídeo é pra você que é mulher negra como eu. Provavelmente a sua autoestima, assim como a minha, deve ter chegado de forma tardia, né? É uma coisa que infelizmente a gente tem em comum. Quando a gente fala das nossas dores e das coisas que nós passamos na nossa infância e adolescência, e tudo mais. Infelizmente essa é uma coisa em comum. (Transcrição de Trecho de vídeo de Luciellen Assis)

A questão da identidade estética é central nas narrativas audiovisuais dessas mulheres. A forma como o racismo afetou as suas 
percepções de si mesmas através de uma visão marginalizada e inferiorizada dos seus corpos é razão de recorrentes discussões nos seus canais. Ao responder à TAG Tour pelo meu corpo, criada e proposta pela criadora de conteúdo Luiza Junqueira, do canal Tá Querida, Gabi Oliveira fala sobre como os seus traços negroides foram motivos para a construção de um ódio às suas próprias características físicas e propõe um questionamento sobre os padrões de beleza:

Falando de forma geral, por todo o meu rosto nós encontramos aquilo que chamamos de traços negroides. Eu tenho nariz largo, a boca grande, arcada dentária protuberante, gengiva escura, além, é claro, da minha pele; para além disso, olhos da cor da noite. [...] Agora eu te pergunto: o que te fez acreditar que esse nariz aqui é feio e este é bonito? E por que os dois não podem ser bonitos? [...]. (Transcrição de Trecho de vídeo de Gabi Oliveira)

Imagem 1 - Vídeo Tour pelo meu rosto - Gabi Oliveira

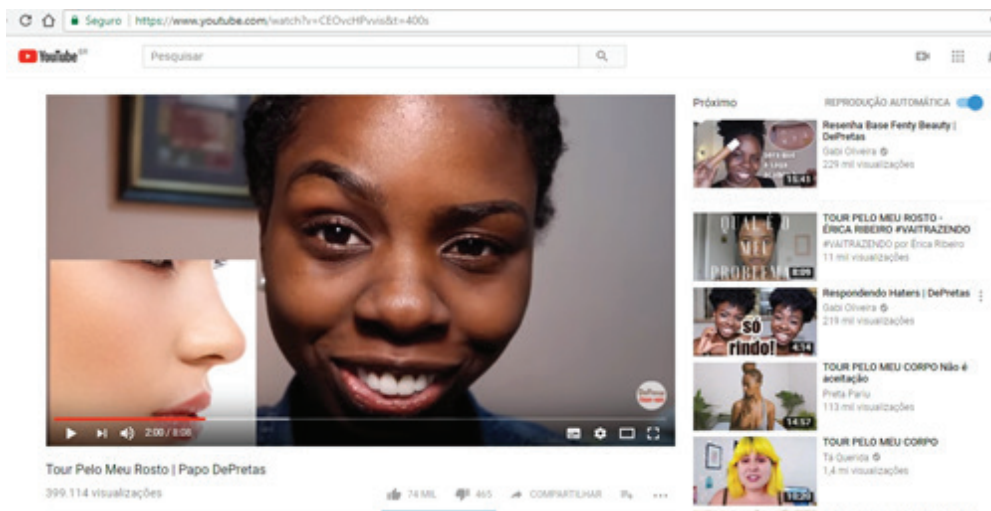

Fonte: própria

Em vídeo posterior, Gabi Oliveira aponta como a produção de vídeos no seu Canal proporciona a ela formas de ajudar outras pessoas a dar novos significados à experiência com o racismo, especialmente no que se refere à estética. A mesma relata como a sua exposição estética ajudou outras mulheres a superar um olhar negativo sobre suas características físicas: 
[...] Essa é uma característica [gengivas escuras], que, na verdade, eu ainda não tinha visto nenhum problema até chegar na internet, e vários e vários relatos de mulheres que falaram que passaram a aceitar melhor a gengiva delas a partir do momento que viram a minha imagem e eu mostrando o sorriso largo [sorriso]. E é realmente muito significativo pra mim perceber como a minha exposição estética ajudou de alguma forma essas mulheres. (Transcrição de Trecho de vídeo de Gabi Oliveira)

A experiência com o racismo ganhou novos contornos com a internet que, segundo ela, expande a experiência com o racismo. Em um vídeo intitulado Respondendo ${ }^{3}$ haters, Gabi Oliveira revela como para ela é difícil produzir conteúdo para a internet, já que, segundo ela, a exposição provocada pelos vídeos nem sempre é positiva. Neste mesmo vídeo Gabi expõe em diferentes imagens comentários de haters, entre os quais, um comentário sobre a sua gengiva: "Sua gengiva e seus dentes são iguais a do meu cachorro".

\section{Imagem 2 - Vídeo Respondendo Haters - Gabi Oliveira}

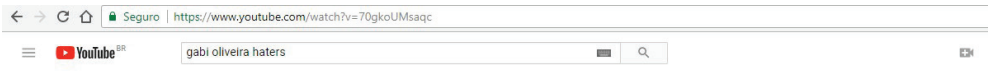

$\equiv$ DouTube ${ }^{\text {BR }}$ gabioliveira haters $\quad$ Q $\quad$ Q
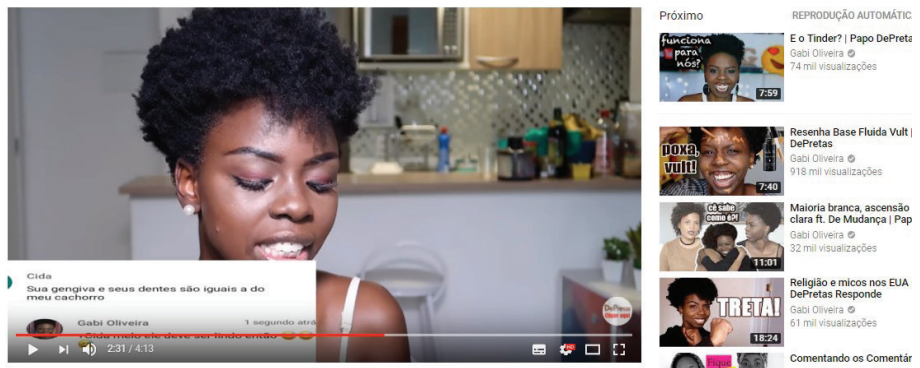

Respondendo Haters | DePretas 220.123 visualizaç̋̋es
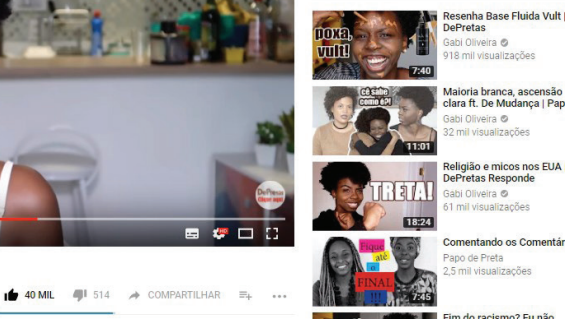

Fonte: Própria

Em seus vídeos, Ana Paula Xongani também aponta o racismo vivenciado e expresso pela violência em torno das suas características físicas. Em um deles, ela afirma que não conseguiu construir

${ }^{3}$ https: / www.youtube.com/watch?v=70gkoUMsaqc 
um vídeo para a mesma Tag "Tour pelo meu corpo: sobre Processos de aceitação". Ana Paula afirma que, ao relembrar das experiências de violência experimentadas por habitar um corpo negro, foi difícil para ela falar sobre a temática proposta pela Tag. Ao relatar sobre como se sentiu ao gravar este vídeo, ela diz: "Foram muitas sensações e aí eu comecei a observar que não era uma negação do meu próprio corpo. Era um medo de expor o meu corpo ao que vinha do outro, ao que vinha de fora. As violências que esse corpo, por ser ele como ele é, já sofreu simplesmente por existir.".

Para ela, estar no Youtube como mulher negra e construir conteúdos sobre aquela Tag, criou desafios específicos que estavam relacionados às questões raciais que a atingem. No vídeo, Ana Paula relata sua experiência e explica as especificidades da sua condição racial: negra e retinta, por muitas vezes comparada a imagens como a de uma formiga, da nega maluca e da Sarah Baartman.

Imagem 3 - Vídeo Tour pelo meu corpo (SQN) - Ana Paula Xongani

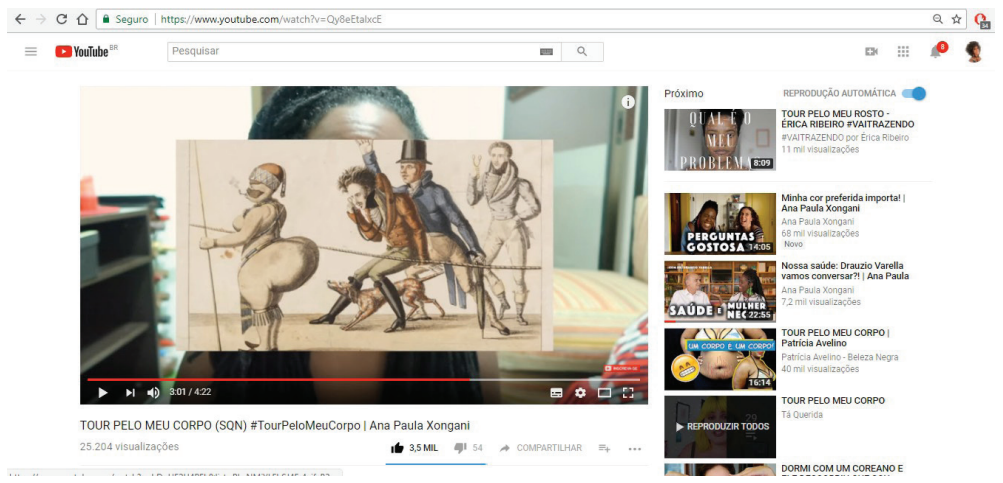

Fonte: Própria

É importante destacar que as narrativas audiovisuais produzidas por essas três mulheres são construídas através de diferentes referências que vão além das suas histórias de vida. Elas exploram textos jornalísticos, documentários, textos acadêmicos, entre outros, para analisar suas experiências como mulheres negras. Isso revela 
que através do fluxo digital em rede elas acessam e compartilham conhecimentos, e significam as suas experiências de vida, base fundamental das suas narrativas. $\mathrm{O}$ digital em rede proporciona para essas mulheres espaços de reflexão e autoria acerca das suas condições sociais e históricas, nos quais o conhecimento científico não é o único mobilizador de reflexões ou de produção de narrativas.

Neste vídeo, em que trata sobre a Síndrome do Impostor, Gabi Oliveira constrói uma rede de relações entre a sua experiência como mulher negra produtora de conteúdo para o Youtube e a síndrome da impostora. Ela explica no vídeo como a sua vivência como mulher negra no Youtube pode estar relacionada com a questão da autoestima da mulher negra. Para isso, faz referência a textos que relacionam tal questão à opressão de gênero e constrói de forma autoral as relações entre a síndrome e a questão racial, ampliando as discussões dos textos por ela encontrados na rede.

Agora eu quero destacar com vocês alguns outros trechos: "A síndrome da
impostora tem muito a ver com essa ideia de que homens fazem tudo muito melhor".
Eu acredito que isso também acontece em relação à branquitude, vocês
não acham? [...] Aqui se a gente substituir "homens" por "brancos" eu
acho que a gente tem tipo a história das Américas. [...] o que eu tô que-
rendo mostrar é que se a gente junta gênero e raça a coisa só piora. E
me causa muito estranhamento nessas matérias que eu li que esses dois
fatores não tenham sido cruzados. (Transcrição de Trecho de vídeo de
Gabi Oliveira)

Gabi Oliveira propõe também nos seus vídeos uma reflexão sobre como o padrão estético atinge as suas experiências sociais, especialmente no que se refere à área afetiva das mulheres negras. Para isso, ela discute e apresenta em um dos seus vídeos as ideias ${ }^{4}$ difundidas em uma dissertação de mestrado sobre a solidão da mulher negra e conjuga os achados da pesquisa com suas experiências cotidianas:

4 Dissertação: A solidão da mulher negra: sua subjetividade e seu preterimento pelo homem negro na cidade de São Paulo. Autora: Claudete Souza. https://www.revistaforum.com.br/wp-content/uploads/2015/09/ cp056761.pdf 
"O que eu acho que aconteceu foi $i^{5}$ que a Claudete deu nome aos bois. Porque eu já tinha visto, já tinha percebido que várias das minhas amigas negras não tinham casado, já tinha percebido que, por exemplo, na igreja as meninas negras demoravam muito mais a namorar do que as outras meninas, a casar. Só que não tinha nome." ${ }^{6}$. Os relatos tecidos por essas mulheres revelam como elas constroem uma rede de relações entre as suas experiências enquanto mulheres negras e os diferentes conhecimentos por elas acessados.

Percebeu-se também nesta pesquisa que as narrativas criadas por essas mulheres possuem um caráter político na medida em que disputam com as "velhas narrativas" construídas sobre as identidades estéticas das mulheres negras e constroem novos sentidos para além do discurso de inferiorização das mesmas. As narrativas audiovisuais analisadas estão centradas em conteúdos antirracistas com foco nas identidades estéticas das mulheres negras e são produzidas com o intuito de constituírem contra-narrativas que ajudem outras mulheres negras nos seus processos identitários. Este processo nos indica que a experiência de construir e compartilhar tais narrativas audiovisuais pode compor uma das dimensões do amplo processo formativo dessas mulheres.

\section{Considerações Finais}

Com este estudo, percebeu-se que as narrativas compartilhadas por mulheres negras no Youtube possuem como eixo central a construção das identidades das mulheres negras e que, ao construí-las e compartilhá-las em rede, essas mulheres conduzem um processo de significação das suas experiências em uma sociedade racista.

A relação estabelecida por elas entre os saberes de suas experiências de vida como mulheres negras, os conhecimentos acadêmicos que adquirem ao longo de suas trajetórias e informações relacionadas que circulam na internet, revelam como os processos formativos são articulados em uma busca de sentido para si e para suas experiências sociais que tem um caráter multirreferencial.

Autora da dissertação

6 https: / / www.youtube.com/watch? $\mathrm{v}=\mathrm{NgNt} 0 \mathrm{GzWCVI} \& \mathrm{t}=420 \mathrm{~s}$ 
Através da pesquisa, foi possível perceber no campo da educação, como a produção destes conteúdos autobiográficos, expressos pelas narrativas audiovisuais, podem articular processos formativos e permitem aos sujeitos, enredados em suas histórias, reencontrar um horizonte biográfico no contexto histórico e político em que se encontram.

\section{Referências}

BONDÍA, Jorge Larossa. Notas sobre a experiência e o saber de experiência. Revista Brasileira de Educação. Campinas, n.19, pp. 20-28. Jan/Fev/Mar/Abr. 2002. Disponível em: <http://educa.fcc.org.br/pdf/rbedu/n19/n19a03.pdf > . Acesso em 11 de fev. de 2016.

BENTES, Ivana. Redes colaborativas e precariado produtivo. online. Revista Periferia. Rio de Janeiro v.1, n.1. p. 53-61. 2009. Disponível em: < http://www.e- publicacoes.uerj.br/index.php/periferia/article/view/3418

CANDAU, Vera Maria (org.). A didática em questão. Petrópolis, Rio de Janeiro: Vozes, 1983.

CARNEIRO, Sueli. Gênero, raça e ascensão social. Revista Estudos Feministas. Ano 3, $2^{\circ}$ semestre, 1995.

DAVIS, A. Mulheres, raça e classe. São Paulo: Boitempo, 2016.

DOMINICÉ, Pierre. A formação de adultos confrontada pelo imperativo biográfico. Educação e Pesquisa, São Paulo, v.32, n.2, p. 345-357, maio/ago. 2006. Disponível em: http://www.scielo.br/scielo.php?pid=\$151797022006000200010\&script=sci_arttext Acesso 04 de fev. de 2016.

FARIAS, I.; SALES, J.; BRAGA, M.; FRANÇA, M. Didática e docência: aprendendo a profissão. 4 ed. Brasília: Liber Livro, 2014.

GOMES, Nilma Lino. Relações étnico-raciais, educação e descolonização dos currículos. Currículo sem Fronteiras, v.12, n.1, pp. 98-109, 2012.

HARAWAY, D. Manifesto ciborgue Ciência, tecnologia e feminismo-socialista no final do século XX In: HARAWAY, Donna; TADEU, Tomaz; HUMZRU, Hari. (org) Antropologia do ciborgue: as vertigens do pós-humano. Belo Horizonte: Autêntica Editora, 2009. https://we.riseup.net/assets/128240/ANTROPOLOGIA+DO+CIBORGUE.pdf 
HIMANEN, Pekka. A ética dos hackers e o espírito da era da informação: a importância dos exploradores da era digital. Rio de Janeiro: Campus, 2001.

HOOKS, Bell. Mulheres negras: moldando a teoria feminista. Revista Brasileira de Ciência Política, nº16. Brasília, janeiro - abril de 2015, pp. 193-210.

JOSSO, M.C. Experiências de vida e formação. Trad. de José Cláudio e Júlia Ferreira. Lisboa: EDUCA, 2002.

JUNGBLUT, Airton Luiz. Práticas ciberativistas, agência social e ciberacontecimentos. Vivência: Revista de Antropologia. n. 45, p. 13-22, 2015.

LEMOS, André. Cibercultura: tecnologia e vida social na cultura contemporânea. Porto Alegre: Sulina, 2010.

LÈVY, Pierre. Cibercultura. Rio de Janeiro: 34, 1999.

MACEDO, Roberto Sidney. Compreender/Mediar a formação: o fundante da educação. Brasília: Liber Livro Editora, 2010.

Atos de currículo e autonomia pedagógica: o socioconstrucionismo curricular em perspectiva. Rio de Janeiro: Vozes, 2013.

RÜDIGER, Francisco Ricardo. Introdução às teorias da cibercultura: perspectivas do pensamento tecnológico contemporâneo. Porto Alegre: Sulina, 2003.

SANTOS, E. Formação de professores e cibercultura: novas práticas curriculares na educação presencial e a distância. Revista da FAEEBA - Educação e Contemporaneidade, Salvador, v. 11, n. 17, p. 113-122, jan./jun., 2002.

\section{TATIANA PAZ}

CV LATTES: http:/ /lattes.cnpq.br/4483960223050442

ORCID: https://orcid.org/0000-0001-8393-9512.E-mail: tatiana.paz@ifce.edu. br telefone: (85) 98147-9797. Endereço: Rua Ana Bilhar 500, Ed. Portal do Alto, ap. 403. Meireles. Fortaleza-CE CEP: 60.160-110

\section{EDUARDO S. JUNQUEIRA}

CV LATTES: http:/ / lattes.cnpq.br/7443323966791424

ORCID: https://orcid.org/0000-0001-7961-5574 e-mail: eduardoj@virtual.ufc. br telefone: (85) 98711-0088

Endereço: Avenida Humberto Monte s/n, Campus do Pici, bloco 901, Fortaleza, CE, CEP: 60440-554 